\title{
Double Free Transverse Upper Gracilis Flap Breast Reconstruction: Advantages of Using LD Flap as a Salvage Solution
}

\author{
Giovanni Bistoni $^{1,2} \cdot$ Francesco Simonacci $^{3} \cdot$ Luca Fiorot $^{4,5} \cdot$ Severiano Marin Bertolín ${ }^{1}$ \\ Received: 6 January 2021 / Accepted: 26 April 2021 / Published online: 12 May 2021 \\ (C) Association of Surgeons of India 2021
}

\begin{abstract}
The lower abdominal tissue is still the most common donor site used for free autologous breast reconstruction. If this site is not available, multiple secondary choices exist. The transverse upper gracilis flap is a valuable choice and it can be used alone or in combination with other flaps. We present a case of a 49-year-old patient who underwent delayed unilateral breast reconstruction by using a double transverse upper gracilis flap. Due to venous thrombosis, the flap inserted in the lower pole was lost. We managed the complication tailoring a latissimus dorsi flap to close the defect. We reported the advantages of the latissimus dorsi flap as a rescue solution and its superior aesthetic result in this particular case. Breast reconstruction with transverse upper gracilis flap in addition to the latissimus dorsi flap allowed us to obtain an adequate breast volume avoiding the use of breast implants as desired by the patient. We thought that the double free transverse upper gracilis flap for delayed, or immediate unilateral reconstruction of small to moderate breast could be a valuable option to avoid the use of implants and when abdominal tissue is not available. However, it should be taken into consideration the shortness of the transverse upper gracilis pedicle, the necessity to perform a retrograde flow anastomosis at the level of the internal mammary, and the discrepancy of skin color tones with the receiving site. The latissimus dorsi flap was an excellent rescue solution and put in evidence the aesthetic superiority of this flap compared to the transverse upper gracilis flap.
\end{abstract}

Keywords Breast reconstruction · Double TUG flap · LD flap · TMG flap · Delayed breast reconstruction

\section{Introduction}

The transverse upper gracilis (TUG) flap could be an indication for reconstruction of small or moderate breasts in women who do not want to have implants, when the abdomen is not an available donor site or who would not accept scars in the abdomen or in the gluteal region. The flap is based on a branch

Giovanni Bistoni

g.bistoni@gmail.com

1 Servicio Cirugía Plástica, Consorcio Hospital General Universitario de Valencia, Valencia, Spain

2 Plastic Surgery Unit, Department of Surgery, Sapienza University of Rome, Rome, Italy

3 UOSD Breast Unit, Macerata General Hospital, AV3, ASUR Marche, Macerata, Italy

4 Department of Surgical, Microsurgical and Medical Science, Plastic Surgery Unit, University of Sassari, Sassari, Italy

5 Department of Plastic Surgery, Spedali Civili Brescia, Brescia, Italy of the medial circumflex femoral artery [1-4]. The vascular pedicle is relatively short, but the flap dissection is quite fast. The internal mammary artery and veins are the recipient vessels most often used for the anastomosis [1]. Compared to other donor sites the dimension of the TUG flap is smaller and the fat pad is thinner. In patients with large breast volumes, one option is to use bilateral TUG flaps for unilateral breast reconstructions. We presented a case of a unilateral delayed breast reconstruction using bilateral TUG free flaps where a latissimus dorsi (LD) flap was used as a rescue solution after the failure of one of the two microsurgical flaps.

\section{Case Presentation}

A 49-year-old (BMI $27 \mathrm{~kg} / \mathrm{cm}^{2}$ and non-smoking) patient presented with a mastectomy scar in her right breast after a skinsparing mastectomy done in 2003 followed by hormone therapy with tamoxifen and radiotherapy with no local or systemic recurrence so far. She denied the use of breast implants for reconstruction. She had previous abdominal surgeries which 
did not allow the use of any abdominal flap. Lipofilling was performed as a first choice but the result was unsatisfactory.

We proposed bilateral TUG flaps to reconstruct her right breast to achieve enough volume maintaining the symmetry of the donor site (Fig. 1).

\section{Surgical Procedure}

The TUG flaps were harvested from the inner thigh bilaterally and transferred to the breast using a double-team approach. We harvested two TUG flaps with a skin island of $8 \times 21 \mathrm{~cm}$ based on the perforating vessels of the main vascular pedicle. A portion of the third rib was removed and both pedicles were end-to-end anastomosed to the internal mammary vessels, the left thigh flap with anterograde flow and the other with retrograde flow.

Both flaps were disepithelized and sculpted accordingly in order to shape the new breast. The TUG anastomized with the anterograde flow was used to reconstruct the upper pole and the flap with the retrograde flow shaped the lower pole. Suction drains were positioned both at the level of the breast and at the level of the thighs.

\section{Complications}

After $24 \mathrm{~h}$ from surgery, the retrograde flow TUG flap used to reconstruct the lower pole was totally congested with signs of epidermolysis and skin necrosis (Fig. 2). There was no chance

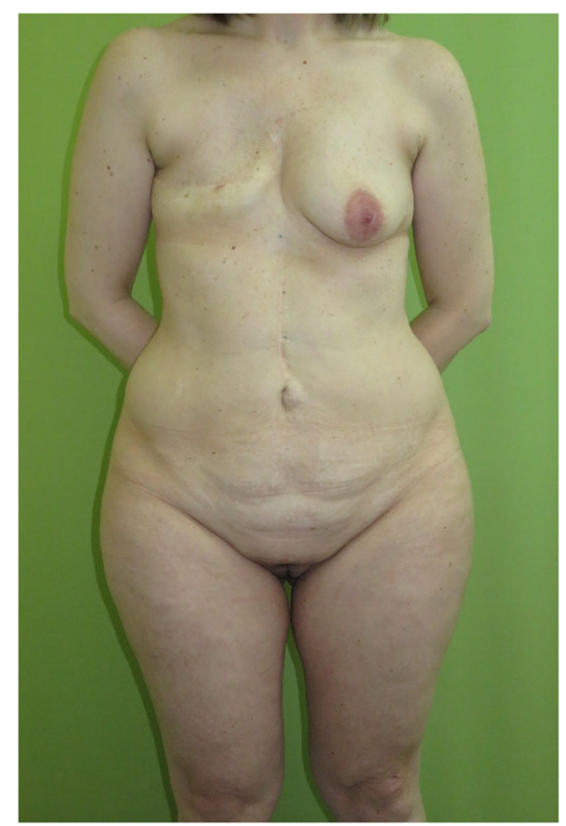

Fig. 1 Preoperative picture of 49-year-old patient (BMI $27 \mathrm{~kg} / \mathrm{cm}^{2}$ and non-smoking) previously underwent skin-sparing mastectomy for breast cancer

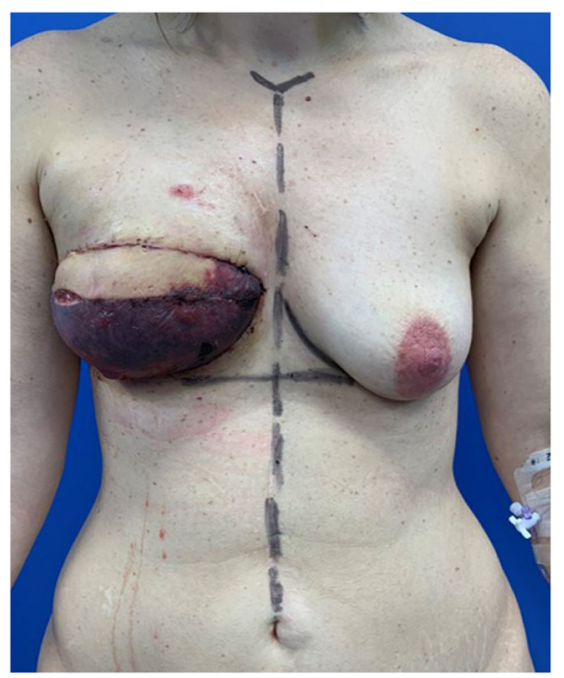

Fig. 2 Lower pole of the breast with signs of epidermolysis and skin necrosis for retrograde flow transverse upper gracilis flap congestion

to save the flap due to the massive venous thrombosis. We therefore decided to cover the defect using a pedicled LD Flap (Fig. 3).

\section{Results}

The LD flap salvage reconstruction highlighted a superior aesthetic outcome due to the much darker skin color of the superior pole TUG flap compared to the skin tone of the residual breast region.

After 8 months, the nipple reconstruction and a mastopexy to symmetrize the contralateral breast were performed. A small amount of lipofilling allowed restoring disparities in volume or contour irregularity. Subsequently the patient was enrolled for the areola pigmentation by medical tattooing which unfortunately has been delayed due to COVID-19 pandemic so far (Fig. 4).

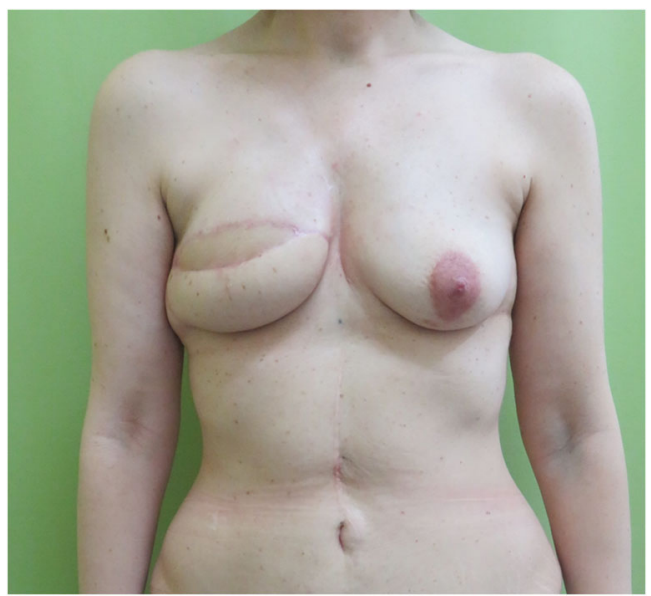

Fig. 3 Breast reconstruction with latissimus dorsi flap (lower pole) and transverse upper gracilis flap (upper pole) 


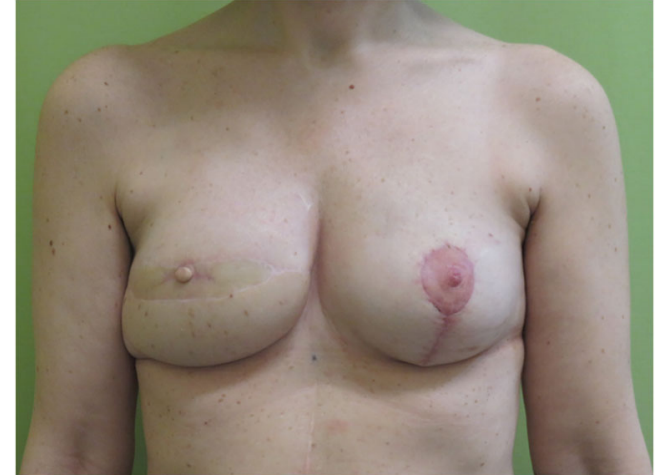

Fig. 4 Nipple reconstruction using a skate flap and a mastopexy to symmetrize the contralateral breast

\section{Discussion}

We faced the challenge of reconstructing a breast with limited resources due to the patient's desire. We decided to use bilateral TUG flaps in order to achieve enough volume while maintaining the symmetry of the donor site.

The failure of the lower pole TUG flap could be due to different causes. Some authors consider that retrograde flow vascular anastomosis is not reliable enough due to the findings describing the peak venous blood velocity resulted to be significantly slower than that of the anterograde vein [5] but according to other studies and cases presented nowadays the retrograde flow is considered safe [6-8]. The LD flap used as a salvage solution is certainly a very good option for breast reconstruction. It has a perfect skin color match with the breast region and, in our case, gives adequate tissue to restore the lower pole of the breast volume.

\section{Conclusion}

Double free transverse upper gracilis flap for unilateral breast reconstruction is indicated in particular cases due to the ease of dissection and the inconspicuous scars. Factors to be considered are the transverse upper gracilis pedicles poor in length, the necessity to perform retrograde flow anastomoses at the level of the internal mammary, and the discrepancy of skin color tones with the receiving site. The latissimus dorsi flap used as a rescue option is an optimal choice to cover the defect left by the failed transverse upper gracilis flap resulting in a superior aesthetic result and restoring an adequate breast volume avoiding the use of breast implants nor fat transfer as desired by the patient.

\section{Declarations}

Ethics Approval Ethical approval was waived by the local Ethics Committee of University of Valencia in view of the retrospective nature of the study and all the procedures being performed were part of the routine care.

Informed Consent The participant has consented to the submission of the case report to the journal.

Conflict of Interest The authors declare no competing interests.

\section{References}

1. ZMI A, Pogorelec D, Planinsek F, Ahcan U (2004) Breast reconstruction by the free transverse gracilis (TUG) flap. Br J Plast Surg 57:20-26

2. Bodin F, Schohn T, Dissaux C, Baratte A, Fiquet C, Bruant-Rodier C (2015) Bilateral simultaneous breast reconstruction with transverse musculocutaneous gracilis flaps. J Plast Reconstr Aesthet Surg 68: e1-e6

3. Buchel EW, Dalke KR, Hayakawa TE (2013) The transverse upper gracilis flap: efficiencies and design tips. Can J Plast Surg 21:162166

4. Saint-Cyr M, Shirvani A, Wong C (2010) The transverse upper gracilis flap for breast reconstruction following liposuction of the thigh. Microsurgery. 30:636-638

5. Kubota Y, Mitsukawa N, Akita S, Hasegawa M, Satoh K (2014) Postoperative patency of the retrograde internal mammary vein anastomosis in free flap transfer. J Plast Reconstr Aesthet Surg 67:205211

6. Seok Nam Y, Hong E, Kwon JG, Kim IB, Eom JS, Han HH (2020) Safety of retrograde flow of internal mammary vein: cadaveric study and anatomical evidence. J Reconstr Microsurg 36:316-324

7. Sugawara J, Satake T, Muto M, Kou S, Yasumura K, Maegawa J (2015) Dynamic blood flow to the retrograde limb of the internal mammary vein in breast reconstruction with free flap. Microsurgery. 35:622-626

8. Tomioka YK, Uda H, Yoshimura K, Sunaga A, Kamochi H, Sugawara Y (2017) Studying the blood pressures of antegrade and retrograde internal mammary vessels: do they really work as recipient vessels? J Plast Reconstr Aesthet Surg 70:1391-1396

Publisher's Note Springer Nature remains neutral with regard to jurisdictional claims in published maps and institutional affiliations. 